\title{
Os Livros Didáticos de Química: Uma Análise das Atividades Investigativas
}

\section{CHEMISTRY TEXTBOOKS: AN ANALYSIS OF INVESTIGATIVE ACTIVITIES}

\author{
Ana Carolina Araújo da Silva (anacarolina.silva@ufjf.edu.br) \\ Universidade Federal de Juiz de Fora (UFJF)
Gahelyka Aghta Pantano Souza (gahelyka@outlook.com) Universidade Federal do Acre (UFAC)
Jéssica Othoni Fernandes Moraes (othonij@gmail.com)
Universidade Federal de Juiz de Fora (UFJF)

\begin{abstract}
Resumo: Nos últimos anos houve um aumento no número de publicações científicas, nacionais e internacionais, que respaldam a relevância das atividades experimentais no processo de ensino e aprendizagem. Nesse sentido, os livros didáticos (LDs) têm disponibilizado uma série de atividades experimentais que sejam economicamente acessíveis à realidade das escolas públicas brasileiras, e que levem em conta a participação dos estudantes no processo de ensino. $O$ presente trabalho tem como objetivo apresentar uma análise que visa identificar os tipos de atividades experimentais presentes nos LDs de química do ensino médio e caracterizar suas possibilidades investigativas. Por meio de uma pesquisa do tipo qualitativa e seguindo os pressupostos teóricos da análise de conteúdo. O corpus de análise são os livros didáticos de química para o ensino médio aprovados pelo programa nacional do livro e do material didático/2018. A pesquisa possui duas etapas principais que são: a exploração e quantificação das atividades experimentais nos LDs e a análise das unidades de registros. A nossa intenção, nesta pesquisa, é produzir uma compreensão crítica e reflexiva sobre as atividades experimentais investigativas presentes nos livros didáticos, além de possibilitar uma ampliação relativa às possibilidades e limitações deste material, especialmente para área de ciências da natureza.
\end{abstract}

Palavras-chave: Análise de Livro Didático; Análise de conteúdo; Atividades experimentais investigativas.

Abstract: In recent years there has been an increase in the number of national and international scientific publications supporting the relevance of experimental activities in the teaching and learning process. In this sense, textbooks (LDs) have provided a series of experimental activities that are economically accessible to the reality of Brazilian public schools, and that take into account the participation of students in the teaching process. This paper aims to present an analysis that aims to identify the types of experimental activities present in high school chemistry LDs and characterize their investigative possibilities. through a qualitative research and following the theoretical assumptions of content analysis. The corpus of analysis are the high school chemistry textbooks approved by the 2018 national textbook and textbook program. The research has two main stages: exploration and quantification of experimental activities in LDs and analysis of units of records. Our intention, in this research, is to produce a critical 
and reflexive understanding about the investigative experimental activities present in the textbooks, besides allowing a relative expansion of the possibilities and limitations of this material, especially for the area of natural sciences.

Keywords: Didactic Book Analysis; Content analysis; Investigative activities.

\section{INTRODUÇÃO}

As atividades experimentais nas aulas de Ciências, não é mais nenhuma novidade e, é relevante, pois permite aos estudantes estabelecerem elos entre as explicações teóricas a serem desenvolvidas em sala de aula e as observações possibilitadas por esse tipo de atividade. Nos últimos anos, inúmeras publicações científicas, nacionais e internacionais, têm respaldado a relevância das atividades experimentais no processo de ensino e aprendizagem. Para Giordan (1999) a elaboração do conhecimento científico apresenta-se dependente de uma abordagem experimental, não tanto pelos temas de seu objeto de estudo, os fenômenos naturais, mas fundamentalmente porque a organização desse conhecimento ocorre preferencialmente nos entremeios da investigação. Dessa forma, aplicar atividades experimentais em sala de aula envolve desenvolver o conceito auxiliando no processo de apropriação de conhecimento.

Outra perspectiva para o desenvolvimento de atividades experimentais é o ensino investigativo. A atividade investigativa foi proposta por John Dewey, cujo objetivo central era propor a experiência a partir da vivência de situações problemas. Essa proposta é muito bem implantada em países da América do Norte e da Europa, enquanto no Brasil, a proposta ainda é pouco implementada nas aulas de Química/Ciências. Isso se deve ao fato de que nem sempre o ensino é relacionado com seu contexto de origem, limitando dessa forma a maneira como os conhecimentos são aprendidos e relacionados com os fenômenos cotidianos (MUNFORD; LIMA, 2007).

Sá, Lima e Aguiar Jr (2011) argumentam que as atividades investigativas são uma estratégia, entre outras, que o professor pode utilizar para diversificar a sua prática no cotidiano escolar. São atividades centradas nos alunos e esses podem desenvolver diversas capacidades, entre elas cita-se: desenvolver a autonomia, tomar decisões, pensar embasados em critérios bem definidos etc. Para esses autores as atividades investigativas são caracterizadas por construir um problema, propiciar a obtenção e a 
avaliação de evidências, valorizar o debate e argumentação, aplicar e avaliar teorias científicas, permitir múltiplas interpretações, entre outras. Segundo Sá e Panzera (2012),

Construir um problema: Um problema é uma situação que conduz a uma indagação para a qual o sujeito não dispõe de uma resposta imediata a ser simplesmente evocada, o que o remete ao envolvimento em um dado processo por meio do qual ele produz novos conhecimentos.

A formulação de um problema permite criar uma expectativa inicial que pode ser negada ou confirmada mediante a obtenção de uma resposta. Um problema pode ser construído pelos alunos, pelo professor, ou pelos alunos com a mediação do professor. O mais importante é que o estudante assuma o problema como seu.

Valorizar o debate e argumentação: Para todo problema autêntico deve existir, provavelmente, uma diversidade de pontos de vista sobre como abordá-lo. Por isso, é natural que uma situação-problema desencadeie debates e discussões entre os estudantes. As ações de linguagem produzidas nessas circunstâncias envolvem afetivamente os estudantes, o que é uma evidência de que eles se apropriaram do problema proposto.

Propiciar a obtenção e a avaliação de evidências: o termo evidências refere-se ao conjunto de observações e inferências que supostamente dão sustentação a uma determinada proposição ou enunciado. Processos de experimentação e observação controlada normalmente são dirigidos à busca e à avaliação de evidências que podem estar disponíveis ao fim do experimento ou em bancos de dados.

Aplicar e avaliar teorias científicas: a apropriação do conhecimento científico por parte dos alunos é demonstrada quando esses recorrem a teorias e modelos para reconhecer e interpretar as evidências encontradas.

Permitir múltiplas interpretações: a diversidade de perspectivas e expectativas que são mobilizadas em uma investigação permite múltiplas interpretações de um mesmo fenômeno e, assim, o processo de produção de consensos e de negociação dos sentidos dá lugar a uma apropriação mais crítica dos conhecimentos da ciência escolar (SÁ; PANZERA, 2012, p.01).

As atividades investigativas podem ter caráter experimental ou não. Nas atividades investigativas experimentais, os roteiros de investigações experimentais podem ser organizados em três abordagens, conforme Sá e Panzera (2012):

Investigação estruturada - Nesta abordagem, o professor propõe aos estudantes um problema para investigar, fornece os procedimentos e os materiais, não os informam sobre os resultados previstos, mas propõe questões para orientá-los a conclusão. Os estudantes devem descobrir relações entre as variáveis ou generalizar de outra maneira dos dados coletados.

Investigação semiestruturada - Nesta abordagem, o professor fornece o problema para investigar e os materiais. Os estudantes devem planejar seu próprio procedimento para resolver o problema, além de chegar as suas próprias conclusões.

Investigação aberta - Nesta abordagem o professor pode propor ou não o tema a ser investigado. $\mathrm{O}$ estudante tem ampla autonomia para a realização da atividade, devendo formular seu próprio problema para investigar, planejar seu procedimento, sistematizar os dados coletados, fazer as interpretações e planejar estratégias de socialização do conhecimento construído (SÁ; PANZERA, 2012, p.02).

O presente artigo tem como objetivo apresentar uma análise que visa identificar os tipos de atividades experimentais presentes nos livros didáticos de Química do Ensino 
Médio e caracterizar suas possibilidades investigativas. Essa pesquisa faz parte de uma pesquisa que visa caracterizar, em detalhes, as atividades experimentais presentes nos livros didáticos de Química para o Ensino Médio aprovados pelo Programa Nacional do Livro e do Material Didático (PNLD) de 2017, Edital 04/2015 e distribuídos nas escolas públicas para o triênio letivo de 2018-2021.

\section{O PAPEL DO LIVRO DIDÁTICO NAS AULAS EXPERIMENTAIS DE QUÍMICA}

Tradicionalmente os livros didáticos constituem-se como um dos muitos elementos recorrentes nas salas de aula, principalmente nas escolas da educação pública. brasileira. $\mathrm{O}$ Brasil é atualmente o país que mais investe recursos financeiros nos processos de seleção, compra e distribuição gratuita, de livros didáticos e os valores ultrapassam R \$ 1bilhão/ano, segundo Rocha (2018),

\footnotetext{
O Programa Nacional do Livro e do Material Didático (PNLD) é considerado o maior programa no cenário mundial pertencente a uma política pública de educação, em que se avalia considerando critérios teóricometodológicos/didático-pedagógicos, e se adquire as obras aprovadas e as distribui sem custos para alunos e professores do ensino básico da rede pública de educação, constituindo-se como meio de universalizar o acesso aos materiais didáticos (ROCHA, 2018, p. 08).
}

Para Quadros, Lélis e Freitas (2015), “o livro didático tem sido um dos recursos mais utilizados pelos professores e muito discutido na literatura. Em algumas escolas, inclusive, ele é a base de toda a prática docente" (p. 105). Esse destaque atribuído ao livro, deve-se ao fato de ser ele um dos principais recursos didáticos, em pleno século XXI, utilizado por professores de diferentes modalidades de ensino, "quando não é a única ferramenta disponibilizada pela escola, como possibilidade de mediação durante o preparo e o desenvolvimento das aulas, dentro e fora do espaço escolar" (SOUZA, 2016, p. 17).

Para Carneiro, Santos e Mól "essa centralidade lhe confere estatuto e funções privilegiadas na medida em que é através dele que o professor organiza, desenvolve e avalia seu trabalho pedagógico de sala de aula. Para o aluno, o livro é um dos elementos determinantes da sua relação com a disciplina" (2005, p. 02).

Segundo Francalanza, Amaral e Gouveia (1987, p. 26), o livro didático pode ser caracterizado como um agente cultural, pois "seleciona conteúdos habitualmente 
considerados relevantes e apropriados às séries escolares para as quais foram elaborados" Além de suas características culturais, conforme denominam os autores, eles apresentam também características especificas que são próprias das áreas de conhecimento ao qual se destinam, como por exemplo, nos livros destinados ao componente curricular Química, neles encontramos representações, exemplos, imagens e textos próprios da linguagem desta ciência, e quase sempre relacionados com o cotidiano do estudante.

A década de 80 no Brasil é marcada pelas pesquisas desenvolvidas com projetos de produção de materiais didáticos e processos de formação de professores, motivando o rompimento com abordagens clássicas dos conteúdos, principalmente os químicos, de maneira que na maioria dos livros didáticos comerciais novas metodologias de ensino foram sugeridas (MORTIMER; SANTOS, 2008).

Surge desse momento, diferentes propostas de livros didáticos, com novas abordagens, quebrando a clássica divisão do ensino de Química brasileiro. E assim, em várias regiões do país, pesquisadores das universidades federais começaram a sugerir materiais didáticos elaborados com base em uma perspectiva "inovadora". As propostas tinham como objetivo principal priorizar a participação dos estudantes em todos os momentos da aula de química, de maneira que o processo de ensino aprendizagem seja uma construção entre professor e estudante.

Os autores então, passam a elaborar obras que articulem a interdisciplinaridade e a contextualização à proposta didático-pedagógica de suas coleções, à medida que buscam por uma organização diferenciada dos textos principais. Nesse contexto, os livros são elaborados com o intuito de não somente estabelecer uma relação com outras áreas do conhecimento, mas também com atividades próprias da Química como a experimentação, proposta nos livros didáticos.

Os editais que norteiam os processos seletivos sempre apontaram um item específico para a experimentação na elaboração das obras didáticas, como no trecho do Edital (BRASIL, 2018) descrito a seguir:

k. apresentar, em suas atividades, uma visão de experimentação que se alinha com uma perspectiva investigativa, que contribua para que os jovens pensem a ciência como campo de construção de conhecimento permeado por teoria e observação, pensamento e linguagem. Nesse sentido, é plenamente necessário que a obra - em seu conteúdo - favoreça a apresentação de 
situações-problema que fomentem a compreensão dos fenômenos, bem como a construção de argumentações que favoreçam tomadas de decisão no exercício da cidadania (BRASIL, 2018, p. 57).

Atualmente existe no mercado editorial brasileiro grande diversidade em livros didáticos, os quais atendem as diversas áreas do conhecimento, com ampla utilização nas séries iniciais, começando com a alfabetização infantil seguindo até a formação de jovens e adultos. O livro agrega conceitos, informações e procedimentos das diversas áreas do conhecimento inclusive a Química, para o professor seu papel é bem mais importante, por propor diferentes metodologias de ensino, concepções de ciência, educação, sociedade e tecnologia. Para o componente curricular supracitado, há a existência de elementos próprios do seu ensino, a saber: a experimentação, a história da Ciência, dentre outros (BRASIL, 2018).

A experimentação é um dos itens que devem estar presente nos livros didáticos de Química, conforme a orientação contida nos Editais que norteiam os processos de seleção, é imprescindível que os autores proponham experimentações "adequadas à realidade escolar" e "alinhadas a uma perspectiva investigativa". De forma que os estudantes pensem "a ciência como campo de construção de conhecimento permeado por teoria e observação, pensamento e linguagem" (BRASIL, 2018, p. 57).

Portanto, a experimentação deve problematizar situações, provocando o diálogo entre o professor, o estudante e os conteúdos trabalhados, de forma que envolva a resolução de problemas resultando na compreensão de conceitos. Assim as atividades experimentais investigativas dos livros didáticos devem estimular o desenvolvimento conceitual dos alunos, bem como sua participação ativa nas aulas experimentais de Química (HODSON, 1994).

\section{METODOLOGIA}

Ao investigar as atividades investigativas presentes nos LDs, pensamos de alguma forma contribuir para a compreensão e possibilidades que essas atividades possam proporcionar para o desenvolvimento dos conceitos científicos em sala de aula. Para atingir os objetivos desta pesquisa, a opção metodológica abordada é de natureza qualitativa, que de acordo com Bogdan e Biklen (1994) pode ser entendida como:

[...] um termo genérico que agrupa diversas estratégias de investigação que partilham determinadas características. Os dados recolhidos são designados 

pessoas, locais, e conversas, e de complexo tratamento estatístico (BOGDAN; BIKLEN,1994, p.16).

Nesse processo de descrição, conhecimento e detalhamento do objeto de estudo, adotamos os pressupostos teóricos da análise de conteúdo (BARDIN, 1995). A análise de conteúdo busca caracterizar as vivências do sujeito e suas percepções sobre um objeto e seus fenômenos, proporcionando assim o levantamento de indicadores (quantitativos ou não) que permitem a partir de processos sistemáticos a produção de inferência de conhecimentos (BARDIN, 1995; CAVALCANTE, 2014). Com base em Bardin (1995) as etapas da análise de conteúdo pressupõem: Primeira etapa: Pré-análise - momento em que ocorre a exploração do material, a identificação das suas características e definição do corpus de análise; Segunda etapa: Inferência - nessa etapa, analisamos as causas e consequências e analisamos o material frente as categorias préestabelecidas; Terceira etapa: Interpretação - é a última fase e envolve compreender os significados das descrições dos dados e informações que ajudam a responder os questionamentos iniciais, relacionando os achados e a fundamentação teórica.

A pré-análise do LDs envolveu a exploração do material, caracterização e definição do corpus de estudo. Para o estudo, utilizamos as características do Ensino por Investigação (SÁ, 2011) que já foram apresentados e são: Construir um problema/situação/problema; Valorizar debate e argumentação; Propiciar a obtenção e a avaliação de evidências; Aplicar e avaliar teorias científicas e Permitir múltiplas interpretações. Essas características são as categorias pré-estabelecidas para a etapa de inferência. $\mathrm{O}$ corpus de análise foram os as atividades experimentais investigativas. No processo de análise dos seis livros aprovados pela PNLD de 2018, nomeamos os livros em LD1, LD2 a LD6. Para a identificação dos livros, utilizamos o título do livro, a Editora e o nome dos autores e/ou coordenadores/organizadores. Portanto, o LD1 corresponde ao Vivá - Química, Editora Positivo, Novais e Tissoni; o LD2, corresponde ao Química, Editora Scipione, Andréa Horta Machado e Eduardo Fleury Mortimer; o LD3, corresponde ao Química - Ser Protagonista, SM, Edições SM; o LD4, corresponde ao Química, Moderna, Ciscato, Pereira, Chemello e Proti; o LD5, corresponde ao Química, Editora Ática, Martha Reis e o LD6, corresponde ao Livro Química Cidadã, AJS, Wildson Santos e Gerson Mól (coordenadores). 
Após a identificação do corpus de análise, iniciamos a etapa da pré-análise que envolveu a quantificação das atividades existentes nos três volumes de cada livro. Após essa etapa, usamos as categorias pré-estabelecidas para distinguir os experimentos: atividades experimentais investigativas (AEI) e atividades experimentais simples (AES). Denominamos os experimentos como (AES), aqueles que não possuía nenhuma das características investigativas. As atividades investigativas foram diferenciadas entre atividades ou experimentos ambos deveriam possuir pelo menos uma das seguintes características: Situação-Problema; Problema e Hipóteses. Todas as AES e AEI foram categorizadas para análise comparativa.

Após a categorização do material de estudo, passamos para a etapa de interpretação (BARDIN, 1995). Essa etapa consiste na análise das unidades de registo. Nesta pesquisa, apresentamos os exemplos de atividades investigativas experimentais como unidades de registro.

\section{RESULTADOS E DISCUSSÃO}

Os resultados desta pesquisa serão apresentados conforme as etapas da metodologia adotada, dividimos esta seção em dois momentos de análise: Préanálise/Inferência e Interpretação. Dessa forma, desejamos evidenciar como a metodologia de análise nos permitiu a compreensão em profundidade do objeto de estudo.

\section{PRÉ-ANÁLISE/INFERÊNCIAS DOS LDS}

No momento da pré-análise dos LDs identificamos todas as atividades experimentais presentes nos três volumes dos LDs. Após a etapa de reconhecimento do corpus de análise, elaboramos um quadro (Quadro 1) para contabilizar a quantidade de atividades experimentais AES e AEI e as características presentes em cada atividade.

No Quadro 1 apresentamos uma descrição quantitativa dos livros LD1 a LD6. Nele podemos observar a quantidade total de atividades experimentais (AE), de atividades experimentais simples (AES) e de atividades experimentais investigativas (AEI), com a quantificação de suas características de atividades investigativas (problema; situação-problema; hipótese) e seus tipos de roteiros (estruturados; semiestruturados; abertos). 
Quadro 1: Quantificação de Atividades Experimentais (AE) dos LDs do PNLD-2018 e suas características

\begin{tabular}{|c|c|c|c|c|c|c|c|c|c|}
\hline \multirow{2}{*}{$\begin{array}{l}\text { LD/ } \\
\text { Vol }\end{array}$} & \multirow{2}{*}{$\begin{array}{c}\text { Tota } \\
\text { l de } \\
\text { AE }\end{array}$} & \multirow{2}{*}{$\begin{array}{c}\text { Tota } \\
\mathbf{l} \\
\text { AES }\end{array}$} & \multirow{2}{*}{$\begin{array}{c}\text { Tota } \\
\mathbf{l} \\
\text { AEI }\end{array}$} & \multicolumn{3}{|c|}{$\begin{array}{l}\text { Tipos de } \\
\text { Características de AI }\end{array}$} & \multicolumn{3}{|c|}{$\begin{array}{c}\text { Tipos de Roteiros } \\
\text { Experimentais }\end{array}$} \\
\hline & & & & $\begin{array}{c}\text { Problem } \\
\quad a\end{array}$ & $\begin{array}{l}\text { Situação } \\
\text { problem } \\
a\end{array}$ & $\begin{array}{c}\text { Hipótese } \\
s\end{array}$ & $\begin{array}{c}\text { Estruturado } \\
s\end{array}$ & $\begin{array}{c}\text { Semiestruturado } \\
s\end{array}$ & Abertos \\
\hline $\begin{array}{l}\text { LD1/ } \\
\text { Vol 1 }\end{array}$ & 10 & 0 & 10 & 10 & 1 & 3 & 10 & 0 & 0 \\
\hline $\begin{array}{l}\text { LD1/ } \\
\text { Vol } 2\end{array}$ & 9 & 0 & 9 & 9 & 0 & 2 & 9 & 0 & 0 \\
\hline $\begin{array}{l}\text { LD1/ } \\
\text { Vol } 3\end{array}$ & 4 & 1 & 3 & 3 & 0 & 0 & 4 & 0 & 0 \\
\hline $\begin{array}{l}\text { LD2/ } \\
\text { Vol } 1\end{array}$ & 32 & 9 & 23 & 16 & 4 & 16 & 30 & 2 & 0 \\
\hline $\begin{array}{l}\text { LD2/ } \\
\text { Vol } 2 \\
\end{array}$ & 36 & 26 & 10 & 2 & 0 & 9 & 36 & 0 & 0 \\
\hline $\begin{array}{l}\text { LD2/ } \\
\text { Vol } 3\end{array}$ & 9 & 4 & 5 & 0 & 0 & 4 & 9 & 0 & 0 \\
\hline $\begin{array}{l}\text { LD3/ } \\
\text { Vol1 }\end{array}$ & 12 & 7 & 5 & 4 & 0 & 3 & 12 & 0 & 0 \\
\hline $\begin{array}{l}\mathrm{LD} 3 / \\
\text { Vol } 2\end{array}$ & 12 & 8 & 3 & 2 & 0 & 2 & 12 & 0 & 0 \\
\hline $\begin{array}{l}\text { LD3/ } \\
\text { Vol } 3 \\
\end{array}$ & 13 & 8 & 5 & 0 & 0 & 5 & 13 & 0 & 0 \\
\hline $\begin{array}{l}\text { LD4/ } \\
\text { Vol } 1\end{array}$ & 7 & 0 & 7 & 1 & 0 & 7 & 6 & 1 & 0 \\
\hline $\begin{array}{l}\text { LD4/ } \\
\text { Vol } 2 \\
\end{array}$ & 5 & 0 & 5 & 2 & 0 & 5 & 5 & 0 & 0 \\
\hline $\begin{array}{l}\text { LD4/ } \\
\text { Vol } 3\end{array}$ & 5 & 0 & 5 & 1 & 0 & 5 & 5 & 0 & 0 \\
\hline $\begin{array}{l}\text { LD5/ } \\
\text { Vol } 1 \\
\end{array}$ & 9 & 3 & 6 & 2 & 0 & 5 & 9 & 0 & 0 \\
\hline $\begin{array}{l}\text { LD5/ } \\
\text { Vol } 2\end{array}$ & 9 & 3 & 6 & 4 & 0 & 3 & 9 & 0 & 0 \\
\hline $\begin{array}{l}\text { LD5/ } \\
\text { Vol } 3 \\
\end{array}$ & 3 & 3 & 0 & 0 & 0 & 0 & 3 & 0 & 0 \\
\hline $\begin{array}{l}\text { LD6/ } \\
\text { Vol } 1 \\
\end{array}$ & 4 & 4 & 10 & 10 & 0 & 7 & 14 & 0 & 0 \\
\hline $\begin{array}{l}\text { LD6/ } \\
\text { Vol } 2 \\
\end{array}$ & 8 & 1 & 7 & 7 & 0 & 1 & 8 & 0 & 0 \\
\hline $\begin{array}{l}\text { LD6/ } \\
\text { Vol } 3\end{array}$ & 4 & 0 & 4 & 4 & 0 & 1 & 4 & 0 & 0 \\
\hline
\end{tabular}

Essa etapa envolveu conhecer os livros didáticos, identificar as atividades e as seções onde os experimentos se encontram nos livros e suas categorizações. A partir do Quadro 1 plotamos o Gráfico 1. 


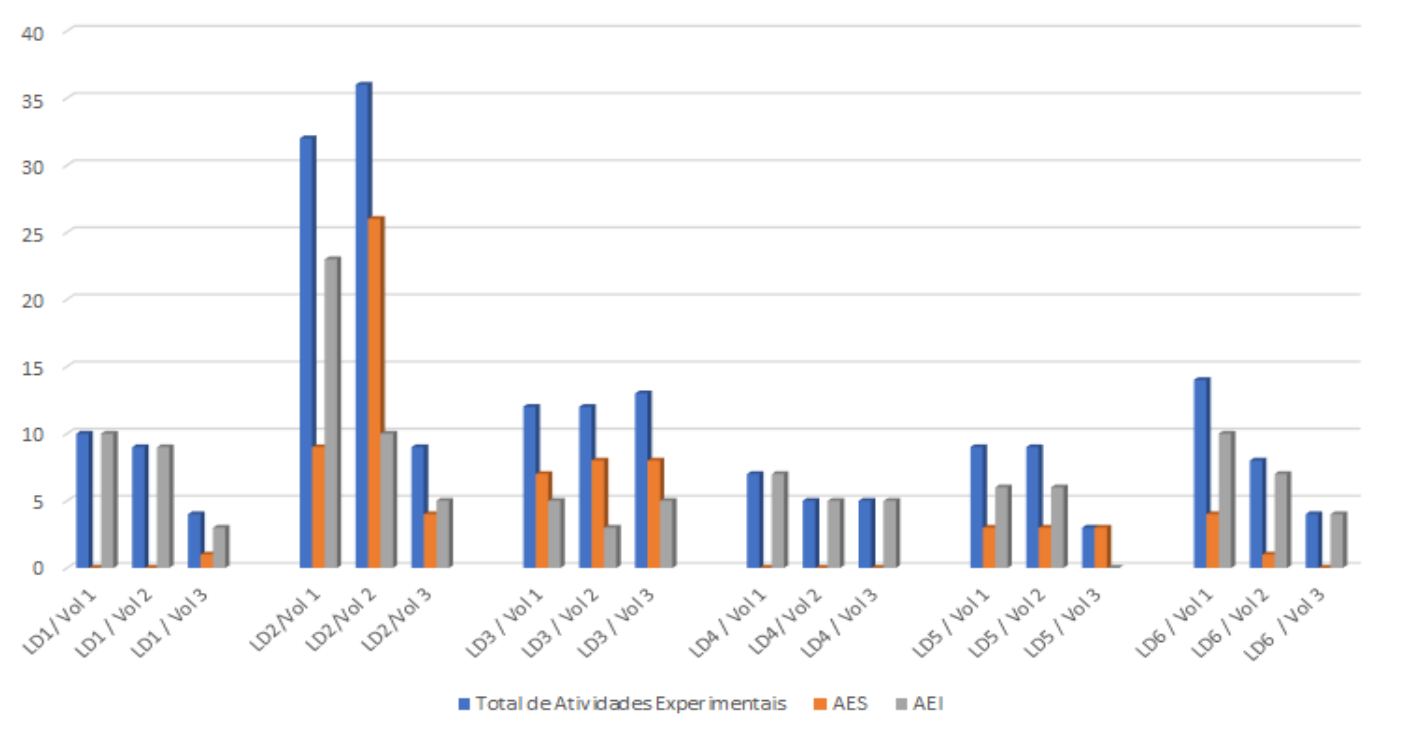

Gráfico 1: Análise das Atividades Experimentais (AE) dos LDs do PNLD-2018.

No Gráfico 1, podemos observar a análise quantitativa geral das atividades experimentais simples (AES) e atividades experimentais investigativas (AEI) dos LDs. Notamos a grande discrepância do LD2 comparado aos demais LDs e que dentro de cada coleção na maioria dos LDs há um decréscimo de atividades experimentais com o crescimento do volume da coleção. Avaliamos esse número expressivo de experimentos do LD2 como uma forma de o professor ter mais de uma opção de atividade experimental. Corroboramos também com Leite (2018) que diz sobre a importância da diversidade de atividade experimentais nos LDs, para o autor essa variedade possibilita ao professor ter mais chances de explorar os conteúdos propostos na experimentação.

Ao compararmos os volumes de cada LD no Gráfico 1, observamos que as atividades experimentais investigativas do Volume 1 dos LDs sobressaem na maioria das coleções, exceto no LD3. Nos LD1 e LD4, são predominantes as atividades experimentais investigativas, no LD1 foram categorizados como problema, situaçãoproblema e hipóteses e no LD4, como problema e hipóteses. O Volume 1 dos LDs é a unidade que trabalha com o $1^{\circ}$ ano do Ensino Médio, tradicionalmente, esse volume aborda os conceitos referentes aos estudos de substâncias e suas transformações, modelo atômico, funções inorgânicas, propriedades e constituição da matéria, tabela periódica, ligações químicas entre outros. 
A análise do Volume 2 dos LDs, identificamos que as atividades experimentais investigativas continuam sobressaindo na maioria das coleções, porém exceto em mais de uma coleção, LD2 e LD3. Nos LD1 e LD4, ainda imperam as atividades experimentais investigativas, categorizados como problemas e hipóteses. O Volume 2 dos LDs é a unidade que trabalho com o $2^{\circ}$ ano do Ensino Médio, tradicionalmente, esse volume trabalha com os conceitos referente aos estudos de unidades de medida química, teoria cinética dos gases, misturas gasosas, estequiometria, estudo das soluções, cinética química, equilíbrio químico, eletroquímica, termoquímica.

Na análise do último volume (Volume 3) dos LDs, a maioria das coleções de LDs (LD1, LD2, LD5 e LD6) já possuem menor quantidade de atividades experimentais em relação aos seus volumes 1 e 2. Destacamos que o LD1 apresenta somente no Volume 3 atividades experimentais tanto simples quanto investigativas, que antes só havia investigativas e foi categorizado somente como problema suas características investigativas neste volume. Nos LD2 e LD3, a quantidade de atividades experimentais simples e investigativas são próximas, e suas características investigativas predominantes são somente hipóteses. Nos LD4 e LD6, predominam as atividades experimentais investigativas, categorizados como problemas e hipóteses, e no LD5 predominam as atividades experimentais simples. O Volume 3 dos LDs é a unidade que trabalho com o $3^{\circ}$ ano do Ensino Médio, tradicionalmente, esse volume trabalha com os conceitos referente aos estudos de funções orgânicas, reações orgânicas, química e alimentos, nomenclatura orgânica, petróleo, isomeria.

\section{INTERPRETAÇÃO DAS ATIVIDADES EXPERIMENTAIS PRESENTES NOS} LDS

Após as quantificações das atividades presentes nos LDs. Passamos para a terceira fase da análise de conteúdo, a interpretação do material (BARDIN, 1995). Nessa etapa de análise, apresentamos as nossas unidades de registro que são os exemplos de roteiros e atividades experimentais investigativas. Para a exploração das unidades de registro utilizamos as categorias pré-estabelecidas para apresentar cada característica das AEIs.

No LD1, identificamos que as atividades investigativas aparecem nas seções do livro que são nomeadas pelos autores como: "Química: prática e reflexão" e na seção “Atividades". Na seção "Química: prática e reflexão" sempre há atividades 
experimentais. Já na seção "Atividades" além de aparecerem atividades investigativas há alguns exemplos de analogia.

No LD1/vol 1 a maior parte das atividades possuem hipóteses, por exemplo, "Levantem hipóteses para explicar por que uma mancha caminha com velocidade maior que outra", porém, o levantamento de hipótese é após a realização da atividade experimental como na Figura 1.

\section{Química: prática e reflexão}

O que acontece com o volume de um gás quando ele é pressionado sem que a temperatura mude?

Figura 1: Exemplo de possibilidade de levantamentos de hipóteses. Fonte: Página 266 do LD1/vol 1.

Na Figura 1, consideramos a pergunta como uma possibilidade de levantamento de hipóteses, o que isso dependerá muito da postura adotada pelo professor durante a aula, ou seja, em estimular os estudantes ou não, a responderem o questionamento antes de realizarem o experimento. Contudo, percebemos que na questão há presença de contexto ou problema, evidenciando duas características do ensino por investigação. É importante ressaltar ainda, que sempre há um destaque com "CUIDADO!" no livro para a segurança nas atividades práticas e/ou no laboratório, onde consta por exemplo: "Cuidado! Use óculos de segurança e avental de mangas compridas. Use luvas refratárias". Os LDs1 volumes 2 e 3 são análogos ao volume 1, diferenciando-se apenas na quantidade dos experimentos e atividades.

O LD2 apresenta uma seção denominada "Investigação". Nessa seção, identificamos as atividades experimentais investigativas e atividades investigativas, e percebemos que algumas destas atividades possuem roteiros abertos. Além disso, na seção "Investigação" geralmente divide-se em partes (A, B, C, D...), trazendo assim mais de uma atividade por seção. Uma outra seção que também apresenta atividades experimentais investigativas é a seção denominada "Reflexão", por fim, nos exercícios estão apenas atividades investigativas. O livro também apresenta projetos investigativos. Na Figura 2, do LD2/vol 1, observamos um exemplo de situaçãoproblema, no qual o experimento apresenta a situação em que os alunos seriam encarregados de selecionar materiais para fabricação de para-choques de automóveis. 
$>1^{\circ}$ acetona, água, ferro, gás de cozinha, gasolina, gesso, hidrogênio, tecido sintético elástico, oxigênio, ouro, papelão, plástico duro (polipropileno), vidro comum e vinagre constituem exemplos de materiais diferentes com características distintas.

a) suponham que vocês sejam encarregados de selecionar materiais para a fabricação de para-choques de automóveis. entre os materiais relacionados acima, quais poderiam ser utilizados com essa finalidade? b) indiquem os materiais mais adequados, mencionando os critérios que vocês consideraram nesta seleção. c) classifiquem os materiais listados acima de acordo comos seguintes critérios:

- materiais que possuem massa;

- materiais que ocupam espaço.

Figura 2: Exemplo de uma das características de AEI. Fonte: Página 20 do LD2/vol 1.

No LD3, há uma seção denominada como “Atividade Experimental”. Nessa seção, encontramos as atividades experimentais. $\mathrm{Na}$ análise do livro identificamos atividades experimentais simples e investigativas. Todas as atividades experimentais presentes no livro possuem roteiros estruturados e objetivos. Há destaque para equipamentos de segurança, para o descarte dos resíduos e destaque "ATENÇÃO!" para o manuseio de compostos perigosos. Na página 279 do LD3/vol 1, consideramos as perguntas 4,5 e 6 como possibilidade de levantar hipóteses, vide Figura 3.

4. Se você colocasse outra bola pequena de esponja de aço no tubo 1, o que aconteceria com ela? E com o sulfato de cobre(II)?

5. O que aconteceria se você colocasse mais bolas de esponja de aço nos tubos 1 e 2?

Figura 3: Exemplo de levantamento de hipóteses. Fonte: Página 279 do LD3/ vol 1.

No LD4 as atividades experimentais estão presentes na seção "Atividade Prática". O livro LD4 menciona na seção "Conheça seu livro" que trabalha com atividades experimentais simples e investigativas. A maioria dos levantamentos de hipóteses propostos pelo livro vem como destaque dentro do livro do professor. Logo, fica a cargo do professor explorar e proporcionar o levantamento de hipóteses em suas aulas. A partir da análise, percebemos que o livro possa estimular o professor a adquirir uma postura investigativa. Em relação as atividades experimentais, identificamos roteiros estruturados e alguns semiestruturados, um exemplo de roteiro semiestruturado encontra-se na página 44 do LD4/vol 1, vide Figura 4, podemos observar que a AEI traz os materiais a serem utilizados, porém no passo 2 do procedimento ele deixa o aluno 
livre para elaborar um procedimento. O livro apresenta um cuidado com o descarte de resíduos.

\begin{tabular}{|c|c|c|}
\hline Material & \multicolumn{2}{|l|}{ Procedimento } \\
\hline $\begin{array}{l}\text { - Uma bola de gude } \\
\text { - Uma bola de } \\
\text { poliestireno expandido }\end{array}$ & \multicolumn{2}{|c|}{$\begin{array}{l}1 \text { Registre em seu caderno quais são as grandezas que devem ser } \\
\text { consideradas na determinação da densidade de um material e quais } \\
\text { são as unidades de medida que podem ser utilizadas em cada caso. }\end{array}$} \\
\hline $\begin{array}{l}\text { (isopor) do mesmo } \\
\text { diâmetro da bola } \\
\text { de gude } \\
\text { Massa de modelar }\end{array}$ & \multicolumn{2}{|l|}{ se voce encontrar alguma ainc } \\
\hline $\begin{array}{l}\text { - Um pedaço de } \\
\text { barbante com cerca }\end{array}$ & \multicolumn{2}{|c|}{$\begin{array}{l}3 \text { Determine as medidas conforme o planejamento anterior e organize os } \\
\text { registros de cada etapa na forma de tabela. }\end{array}$} \\
\hline $\begin{array}{l}\text { de } 12 \text { centímetros de } \\
\text { comprimento }\end{array}$ & \multicolumn{2}{|c|}{$\begin{array}{l}4 \text { Construa em seu caderno uma tabela para organizar os valores das } \\
\text { grandezas medidas e o cálculo das densidades. }\end{array}$} \\
\hline $\begin{array}{l}\text { - Uma régua de } \\
15 \text { centímetros } \\
\text { - Uma proveta ou } \\
\text { recipiente graduado } \\
\text { - Palitos de churrasco }\end{array}$ & \multicolumn{2}{|c|}{$\begin{array}{l}5 \text { Modele a massa nos mesmos formato e tamanho da bola de gude. } \\
\text { Mergulhe cada um dos materiais a serem estudados em um copo (ou } \\
\text { béquer) com cerca de } 200 \mathrm{~mL} \text { de água. Copie a tabela abaixo em seu } \\
\text { caderno e anote suas observações. }\end{array}$} \\
\hline \multirow{3}{*}{$\begin{array}{l}\text { - Balança } \\
\text { Béquer ou copo } \\
\text { transparente de } \\
\text { plástico } \\
\text { Água }\end{array}$} & Material & $\begin{array}{l}0 \text { que ocorre quando o material é } \\
\text { mergulhado no copo com água? }\end{array}$ \\
\hline & Bola de gude & $\square$ \\
\hline & Bola de poliestireno expandido & ש \\
\hline
\end{tabular}

Figura 4: Exemplo de tipo de roteiro semiestruturado.

Fonte: Página 44 do LD4/vol 1.

No LD5 as atividades experimentais aparecem na seção "Experimento" e a autora define os experimentos como investigativos. Em alguns experimentos aparece o alerta de "CUIDADO!" dando algumas instruções aos estudantes e aparece um contexto explicativo do experimento e não um problema. O experimento do LD5/vol 2 (vide Figura 5), dependerá da postura do professor em utilizar a pergunta da imagem antes da realização do experimento para haver levantamento de hipóteses, porém o classificamos como AES. 


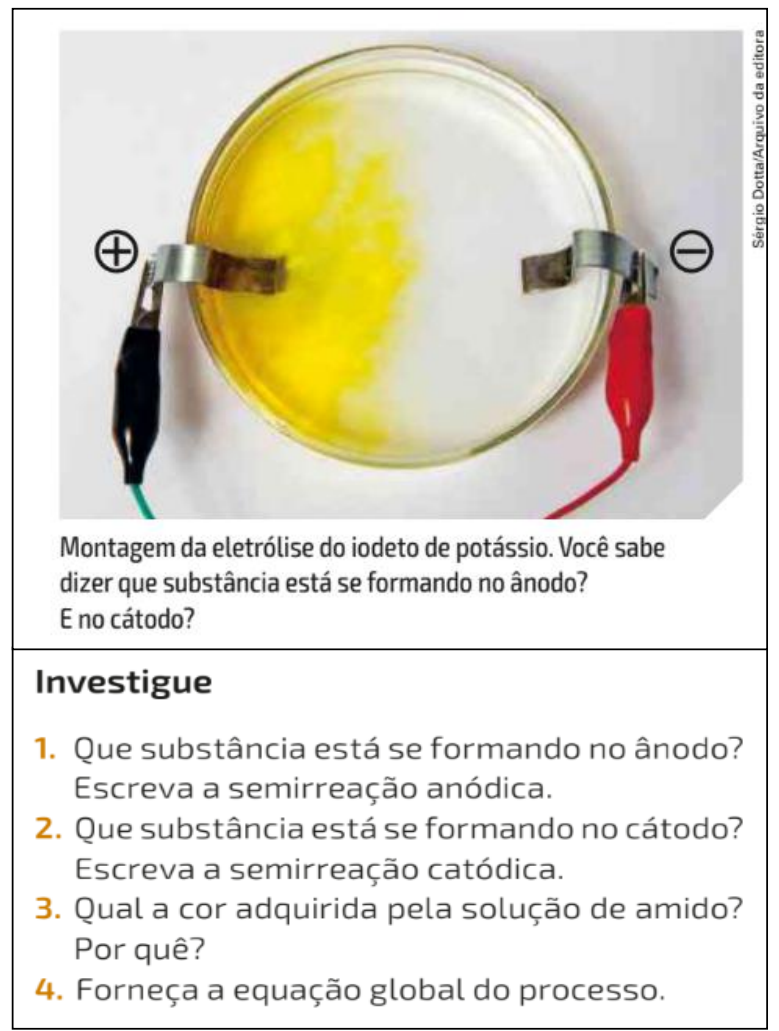

Figura 5: Exemplo de levantamento de hipótese que depende da postura do professor.

Fonte: Página 275 do LD5/vol 2.

No LD6 as atividades experimentais estão presentes na seção "Atividade Experimental", o livro trabalha com atividades experimentais simples e investigativas. Os autores definem os experimentos como investigativos. Alguns experimentos trazem o lembrete "Consulte as normas de segurança no laboratório, na última página deste livro". Na maioria dos experimentos há um problema (pergunta no título da prática). E os experimentos trazem os símbolos, como de compostos de inflamáveis, entre outros. Na Figura 6 podemos ver um exemplo de problema (pergunta no título). Leite “considera que a presença de um título contribuiria para nortear os alunos sobre o que seria possível se alcançar com a experimentação em questão" (2018, p.68). Onde este problema pode provocar interesse no aluno em querer aprender aquele conteúdo, que o aluno tome aquele problema como seu e queira solucioná-lo e a Figura 6 também demonstra um exemplo do símbolo, presente na página 204 do LD6/vol 3. 


\section{Atividade Experimental}

\section{Líquidos podem atacar metais?}

Este experimento poderá ser feito em grupo, na sala de aula ou no laboratório.

\section{Materiais}

- 8 béqueres (ou copos de vidro)

- 1 esponja de palha de aço fina dividida em 4 pedaços

- 4 clipes metálicos

- Solução de sulfato de cobre $1 \mathrm{~mol} / \mathrm{L}\left(\mathrm{CuSO}_{4} \cdot 5 \mathrm{H}_{2} \mathrm{O}\right)$

- Água destilada (água para bateria)

- Solução de sacarose $1 \mathrm{~mol} / \mathrm{L}$ (açúcar)

- Solução de cloreto de sódio $1 \mathrm{~mol} / \mathrm{L}(\mathrm{NaCl})$

Figura 6: Exemplo de uma das características de AEI. Fonte: Página 204 do LD6/vol 3.

Em geral, os LDs 1, 4,5 e 6 possuem mais de um experimento em alguns capítulos e o LD2 possui mais de um experimento na maioria de seus capítulos. De acordo com Leite, “considera-se como ponto positivo o fato de alguns capítulos sugerirem mais de um experimento a ser realizado, o que possibilita ao professor ter mais chances de explorar os conteúdos propostos na experimentação” $(2018$, p.68).

$\mathrm{Na}$ maior parte dos experimentos, as coleções de LDs trazem sugestões de onde aplicar os experimentos e os cuidados a serem tomados com os reagentes utilizados, também indicam como os resíduos devem ser descartados, porém não explicam o porquê do descarte de tal modo.

\section{CONSIDERAÇÕES}

Neste artigo, apresentamos uma pesquisa voltada ao estudo das atividades experimentais investigativas e roteiros presentes nos livros didáticos de Química para o Ensino Médio. A pesquisa possui duas etapas principais que são: a exploração e a quantificação das atividades experimentais nos LDs e a análise das unidades de registros. Na fase de análise das unidades de registros podemos perceber que os livros possuem uma ou duas seções para as atividades experimentais investigativas. Acreditamos que esse estudo possa contribuir com a produção de conhecimento dos 
professores em formação inicial e continuada. A nossa intenção, nesta pesquisa, é produzir uma compreensão crítica e reflexiva sobre as atividades experimentais investigativas presentes nos livros didáticos, além de possibilitar uma ampliação relativa às possibilidades e limitações deste material, especialmente para área de Ciências da Natureza.

Compreendemos, que a experimentação investigativa deve permitir a participação ativa e protagonista dos estudantes durante as aulas, de forma que eles possam propor discussões argumentando sobre a problemática em questão. Os estudantes são os responsáveis por formularem hipóteses, planejarem o experimento, coletarem e analisarem os resultados obtidos bem como propor conclusões sobre o fenômeno estudado. Portanto, quando o docente selecionar uma atividade experimental investigativa deverá pensar nas formas de condução da atividade, nas abordagens propiciadas durante a realização da atividade experimental, nos questionamentos, nas discussões e nas reflexões fomentadas durante o processo de aprendizagem (GRÜNFELD DE LUCA, APARECIDA DOS SANTOS, DEL PINO, J.; CÂMARA PIZZATO, 2018).

A partir do que acreditamos ser experimentação investigativa e, analisando as atividades experimentais dos livros didáticos de química, observamos que nem todos eles atendem aos critérios para o desenvolvimento de uma atividade experimental investigativa, pois na maioria das vezes orientam os estudantes durante $o$ desenvolvimento da experiência, não pelo roteiro que é proporcionado no livro, mas durante o desenvolvimento da atividade, direcionando os alunos a um resultado já conhecido por eles. Dessa forma, os experimentos passam a ser realizados, apenas, para a comprovação da teoria que foi trabalhada no mesmo capítulo ou unidade do livro, não favorecendo a discussão e a proposição de novas conclusões para o fenômeno observado durante a atividade prática e assim distanciando a investigação da prática docente.

\section{REFERÊNCIAS}

BARDIN, L. Análise de conteúdo. Edições 70, Lisboa: Persona, 1995.

BOGDAN, R.; BIKLEN, S. Investigação Qualitativa em Educação: uma introdução à Teoria e aos Métodos. Portugal: Porto, 1994. 
BRASIL. Edital de Convocação para o Processo de Inscrição e Avaliação das obras didáticas para o Programa Nacional do Livro Didático PNLD 2018 - Ensino Médio. Brasília: Ministério da Educação, Secretária de Educação Básica e Fundo Nacional do Desenvolvimento da Educação, 2018.

CARNEIRO, M. H. S.; SANTOS, W. L. P.; MÓL, G. S. Livro Didático Inovador e Professores: Uma Tensão a ser Vencida. Ensaio Pesquisa em Educação em Ciências, v.07, n.02, p. 101-113, mai/ago, 2005.

CAVAlCANTE, R. B.; CALIXTO, P.; PINHEIRO, M. M. K. Análise de conteúdo: considerações gerais, relações com a pergunta de pesquisa, possibilidades e limitações do método. Inf. \& Soc.:Est., João Pessoa, v.24, n.1, p. 13-18, jan./abr. 2014

FRANCALANZA, H.; AMARAL, I.A.; GOUVEIA, M.S.F. O Ensino de Ciências no Primeiro Grau. São Paulo: Atual, 1987.

GIORDAN, M. O Papel da Experimentação no Ensino de Ciências. Química Nova na Escola, v. 10, p. 43-49, 1999.

HODSON, D. Hacia un Enfoque Más Crítico Del Trabalho de Laboratorio. Enseñanza de Las Ciencias, 12(3), p. 299-313. 1994.

LEITE, B. S. A experimentação no ensino de química: uma análise das abordagens nos livros didáticos. Educación Quimica. v. 29, nº. 3, p. 61 - 78, 2018.

GRÜNFELD DE LUCA, A.; APARECIDA DOS SANTOS, S.; DEL PINO, J.; CÂMARA PIZZATO, M. Experimentação contextualizada e interdisciplinar: uma proposta para o ensino de ciências. Revista Insignare Scientia - RIS, v. 1, n. 2, 22 ago. 2018.

MORTIMER, E. F.; SANTOS, W.L.P. Políticas e Práticas de Livros Didáticos de Química: o processo de constituição da inovação x redundância nos livros didáticos de Química de 1833 a 1887. In ROSA, M.I.P.; ROSSI, A.V. (Orgs.) Educação Química no Brasil: memorias, políticas e tendências. Campinas-SP: Átomo, 2008.

MUNFORD, D.; LIMA, M. E. C. C. E. Ensinar ciências por investigação: O que estamos de acordo?. Ensaio Pesquisa em Educação em Ciências, v. 9, p. 20, 2007.

QUADROS, A. L.; LÉLIS, I. S. S.; FREITAS, M. L. A Construção de Explicações Por Estudantes a partir do uso de um Material Didático Temático. In: QUADROS, A. L.; FILHO, F. F. D. (Org.). Ações Construtivas em Química: compartilhando experiências. Campina Grande: EDUEPB; São Paulo: Livraria da Física, 2015.

ROCHA, E. F. da. O Programa Nacional do Livro Didático como Produto de Interesses Políticos, Econômicos e Pedagógicos: Um Estudo Sobre os Livros Digitais de Química. Tese de Doutorado. Universidade Federal de Mato Grosso, Programa de PósGraduação em Educação em Ciências e Matemática, Cuiabá, 2018.

SÁ, E. F. de; LIMA, M. E. C. C.; AGUIAR JÚNIOR, O. G. de. A Construção de Sentidos para o termo ensino por Investigação no Contexto de um curso de Formação. Investigações em Ensino de Ciências (ONLINE), v. 16, p. 79-102, 2011.

SÁ, E. F. de; PANZERA, A. C.; Vivência prática na elaboração de uma atividade investigativa de Ciências. PDEB- Programa de Desenvolvimento da Educação Básica, 2012. 
SOUZA, G. A. P. Influências de uma política pública educacional na transformação de uma obra didática de química. Dissertação de Mestrado. Instituto de Educação, Universidade Federal de Mato Grosso, Cuiabá, 2016. 